2nd International Conference on Ultrafine Grained \&

Nanostructured Materials (UFGNSM)

International Journal of Modern Physics: Conference Series

Vol. 5 (2012) 670-678

(C) World Scientific Publishing Company

DOI: $10.1142 / \mathrm{S} 2010194512002619$

\title{
OPTIMIZATION OF NANOSTRUCTURED BLACK ELECTROLESS Ni-P COATING FOR SOLAR ABSORBER
}

\author{
M. HOSSEINI NAJAFABADI* \\ MSc, Department of Materials Engineering, Isfahan University of Technology, \\ Isfahan 84156-83111, Iran \\ m.najafabadi@ma.iut.ac.ir \\ F. ASHRAFIZADEH \\ Professor, Department of Materials Engineering, Isfahan University of Technology, \\ Isfahan 84156-83111, Iran \\ ashrafif@cc.iut.ac.ir \\ M. MONIRVAGHEFI \\ Associate Professor, Department of Materials Engineering, Isfahan University of Technology, \\ Isfahan 84156-83111, Iran \\ vagh-mah@cc.iut.ac.ir
}

\begin{abstract}
High solar absorber coatings of Ni-P on aluminum substrate have been fabricated by electroless technique as an alternative to complex PVD coatings. For this purpose, the Ni-P coating was deposited on commercially pure aluminum and then blacking process was carried out. Upon heat treatment, the amorphous structure of the coatings transformed to a nanocrystalline structure which is accompanied by variation in properties. The phase structure of the coatings was studied by X-ray diffraction; the crystallite size measured by using Sherrer method indicated an average crystallite size of about $15 \mathrm{~nm}$ with an increase in hardness. Morphological studies of coatings were performed by scanning electron microscopy. The coatings generally had a sound, crack-free surface with a thickness value of around $10 \mu \mathrm{m}$. The optical properties of the coatings were determined by means of spectrophotometer. The black electroless nickel possessed higher absorption in the range of visible light, with a coefficient in the order of 0.98 . The results of this study indicate that the coating process described herein is suitable as solar absorber coating.
\end{abstract}

Keywords: Electroless nickel; Nanostructure; Solar absorber coating; Heat treatment.

\footnotetext{
* Corresponding author. Tel.: +98 3312650804; fax: +98 3113912752.

E-mail address: m.najafabadi@ma.iut.ac.ir (M. Hosseini Najafabadi)
} 


\section{Introduction}

In recent years, there were a lot of research in colors and coatings for solar cell application. Because of high absorption, low cost, ease of manufacture, Ni coatings were used more than other coatings. Several methods like electroless ${ }^{1}$, sol-gel ${ }^{2}$, anodize ${ }^{3}$ and electroplating ${ }^{4}$ were used to prepare black Ni coatings.

The electroless deposition of nickel in bath containing hypophosphite was first noted by Wurtz in 1844, but it was not applied on an industrial scale until an accidental rediscovery of the technique by Brenner and Riddell in 1946. ${ }^{5,6}$ The unique combination of properties of electroless nickel coating such as corrosion and wear resistance, hardness, lubricity, bondability and uniformity of deposit regardless of geometry of the substrate makes it ideal for a wide spread application in metal finishing industries. ${ }^{7-10}$ Electroless nickel plating is an autocatalytic process that produces a nickel deposit on certain catalytically active substrate using a controlled chemical reaction. ${ }^{9-11}$ Coatings produced with this process are not stable thermodynamically and consist of amorphous and crystalline phases. Amount of amorphous phase will be increase, when phosphorous content access. ${ }^{11-13}$

Upon heat treatment, the amorphous structure of the coating transforms to a nanocrystalline structure with formation of nickel and nickel phosphide $\left(\mathrm{Ni}_{3} \mathrm{P}\right)$. The nickel phase provides toughness to the matrix and the nickel phosphide particles increase the hardness of the coating. ${ }^{5}$ Crystallite size is a function of temperature and time of the heat treatment cycle. ${ }^{14} \mathrm{Ni}_{3} \mathrm{P}$ forms at a temperature above $200{ }^{\circ} \mathrm{C}$ and when annealing is conducted at a temperature higher than $400{ }^{\circ} \mathrm{C}$, agglomeration of the particles of this intermetallic compound occurs. ${ }^{15}$

Black electroless Ni-P coatings have been studied by previous researchers for different applications. ${ }^{1}$ Their experimental findings indicate that these coatings possess higher solar absorption compared to other coatings, but they have not been considered seriously for solar power applications.

In this study, the effect of heat treatment and formation of nanocrystalline structure upon roughness, hardness and absorption of coating was evaluated and absorption coefficients of coatings were compared with commercially PVD coatings.

\section{Experimental Procedure}

\subsection{Materials and chemicals}

Aluminum alloy test specimens of AA-1100 of the size of $50 \times 50 \times 1 \mathrm{~mm}$ were used for obtaining high solar absorber black electroless nickel coating. Chemical composition of Aluminum alloy 1100 was noted in Table 1. 
Table 1. Chemical composition of Aluminum alloy 1100.

\begin{tabular}{lllllll}
\hline Element & $\mathrm{Al}$ & $\mathrm{Fe}$ & $\mathrm{Cu}$ & $\mathrm{Mn}$ & $\mathrm{Si}$ & $\mathrm{Zn}$ \\
\hline Wt $\%$ & Bal. & 0.40 & 0.12 & 0.05 & 0.30 & 0.1 \\
\hline
\end{tabular}

Schluter Electroless commercially solution SLOTONIP 70A was used for coatings. Parameters of electroless bath were given in Table 2.

Table 2. Bath electroless parameters.

\begin{tabular}{cc}
\hline Temperature $\left({ }^{\circ} \mathrm{C}\right)$ & $85-90$ \\
\hline $\mathrm{PH}$ & $4.8-5$ \\
\hline Agitation speed $(\mathrm{rpm})$ & 750 \\
\hline Deposition rate $(\mu \mathrm{m} / \mathrm{h})$ & $18-22$ \\
\hline
\end{tabular}

$50 \times 50 \times 1 \mathrm{~mm}$ samples were prepared. First samples were grinded mechanically by abrasive paper and then solvent degreasing using Acetone was performed in an ultrasonic bath at room temperature for $10 \mathrm{~min}$. Alkaline cleaning was done to remove surface oxides in a $10 \% \mathrm{NaOH}$ solution at room temperature for $10 \mathrm{~min}$. Water rinsed. After that acid cleaning was performed for $3 \mathrm{~min}$ in a solution of sulphuric acid $20 \mathrm{ml} / \mathrm{L}$, hydrofluoric acid $12.5 \mathrm{ml} / \mathrm{L}$ and nitric acid $25 \mathrm{ml} / \mathrm{L}$ operating at room temperature. Water rinsed. Finally, to activate the surface, samples were immersioned in $\mathrm{HCl} 30 \%$ for 1 min. After water rinse, samples were entered to electroless bath.

Some of coated samples were heat treated at $300{ }^{\circ} \mathrm{C}$ for 3 hour in Argon atmosphere at a cylindrical furnace. Finally, blackened process was performed on as plated and heat treated coatings. This process was performed by immersion of the samples in 9 Molar nitric acid at $40{ }^{\circ} \mathrm{C}$ for $20 \mathrm{sec}$ (As plated samples) and $10 \mathrm{sec}$ (Heat treated samples).

\subsection{Evaluation of coatings}

The structure evaluation of coatings before and after heat treatment were analyzed by X-ray diffraction model Philips Expert-MPD, $40 \mathrm{KV}, 30 \mathrm{~mA}$ and $\mathrm{CuK} \alpha \quad(\lambda=1.542)$. Crystallite size of coatings was measured in full width half maximum (scherrer low) using the following equation:

$$
\beta \cos \theta=\frac{0.9 \lambda}{D}
$$


Where $\theta$ is the Bragg diffraction angle, $D$ the average crystallite size, $\varepsilon$ the average internal strain, $\lambda$ the wave length of the radiation used $(0.15406 \mathrm{~nm}), \beta$ the diffraction peak width at half maximum intensity.

Coatings morphology and thickness were characterized by scanning electron microscopy (SEM) model XL30. Coatings hardness before and after heat treatment were measured with a micro hardness tester model Leitze Wetzlar. Vickers hardness numbers were obtaining by averaging five measurements on each specimen with a load $100 \mathrm{~g}$ for $15 \mathrm{~s}$ indentation. Roughness of coating's surface before and after blackening was determined by roughness tester Mitutoyo model $\mathrm{Sj}$-201, Japan. Roughness numbers were obtaining by averaging five measurements on each specimen. The optical properties of coatings were measured using a spectrophotometer model CE-7000A. Radiation reflected by the samples was measured in wave length between $300-2000 \mathrm{~nm}$ at an angle of $8^{\circ}$ from normal.

\section{Results and Discussion}

\subsection{Effect of heat treatment on structure and hardness of the coating}

The X-ray diffraction patterns of both as-plated and heat treated samples are shown in Fig. 1. As it can be seen, the as-plated coating (Fig. 1-a) holds a mixture of amorphous and crystalline phases. Diffraction lines in this graph were generated by overlapping of a broad matrix peaks in diffraction angels between 35 to $55^{\circ}$ and two high intensity peaks contributed aluminum and nickel. The sharp XRD peak presents Ni (111) and the broadened peak reveals the presence of an amorphous phase. $\mathrm{Ni}(111)$ peak has the highest intensity of all the electroless $\mathrm{Ni}-\mathrm{P}$ coatings deposited from the baths in which sodium hypophosphite is the reducing agent and sodium citrate or glycine is the complexion agent. $^{16}$

The X-ray diffraction pattern of heat treated sample is shown in Fig. 1-b. It is clear that the amorphous structure of the coating has transformed into a nanocrystalline structure. The amorphous phase of the coating has been replaced by Ni crystalline (fcc structure) and nickel phosphide $\left(\mathrm{Ni}_{3} \mathrm{P}\right.$ with tetragonal structure). In the XRD patterns for the electroless Ni-P coatings after heat treatment at $300{ }^{\circ} \mathrm{C}$ for $3 \mathrm{~h}$, (111) peak becomes sharper in comparison with the coatings not subjected to heat treatment (Fig. 1. a). This indicates an increase in the degree of crystallity of the coatings.

The peaks for plane $\mathrm{Ni}(311)$ and (222) are intensified and a nickel phosphide $\left(\mathrm{Ni}_{3} \mathrm{P}\right)$ phase appears. The crystallite size measured by means of Sherrer method indicated an average size of about $15 \mathrm{~nm}$. Due to rather low thickness of the coating (i.e. $\mathrm{t}<15 \mu \mathrm{m}$ ), main peaks of aluminum substrate appeared in the XRD pattern. 


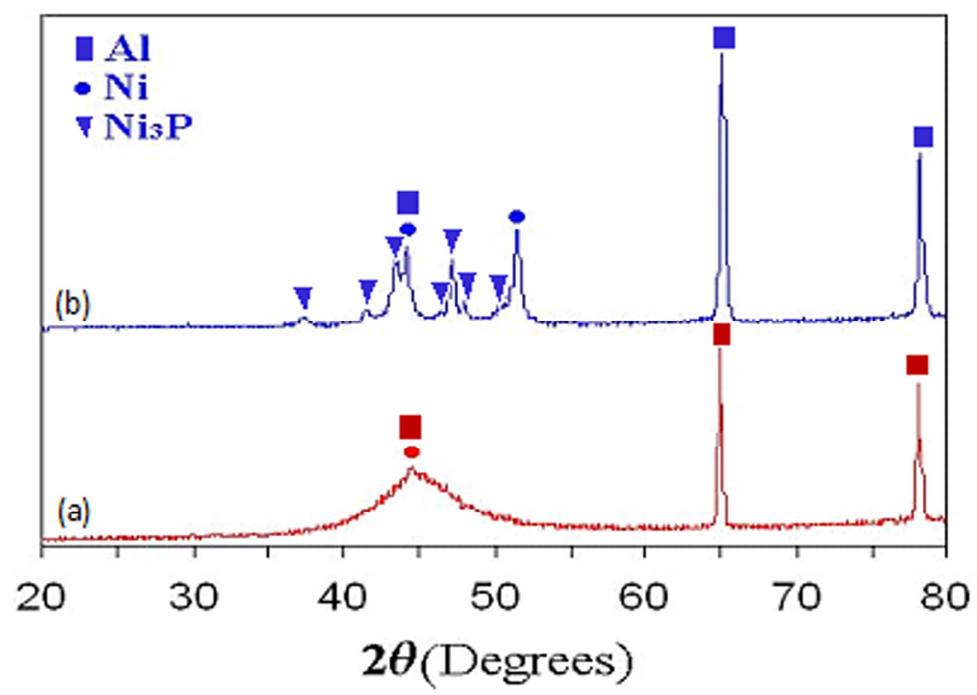

Fig. 1. X-ray diffraction of samples: (a) as plated and (b) heat treated at $300^{\circ} \mathrm{C}$ for $3 \mathrm{~h}$.

Average micro hardness of as plated coating was 580 Vickers. Hardness of the coating was increased to 1050 Vickers after heat treatment at $300^{\circ} \mathrm{C}$ for $3 \mathrm{~h}$. This is due to formation of $\mathrm{Ni}_{3} \mathrm{P}$ stable phase after heat treatment. ${ }^{5,7} \mathrm{Ni}_{3} \mathrm{P}$ is a hard ceramic phase with nano scale grain size. ${ }^{7}$

\subsection{Effect of blackening process on morphology and structure of the coating}

Surface morphology of as plated and black coatings is shown in Fig. 2. Surface morphology of the coatings was similar to Cauliflower and Orange-peel. This structure is very common in electroless Ni-P coatings. ${ }^{17}$ As seen in Fig. 2, after blackening process, uniformity of the coating was decreased. Roughness of as plated coating was about $0.6 \mu \mathrm{m}$ and after blackening process it exceed to $0.95 \mu \mathrm{m}$ and roughness of substrate was $0.75 \mu \mathrm{m}$.

The surface morphology plays a crucial role in obtaining the high absorptance coating. The micrographs show the 'stalagmite-like' structure. The morphology of black nickel depends on the phosphorous contents of the bath. The coating with low phosphorous produces a very pronounced 'crater' morphology whereas the one with high phosphorous content holds a 'stalagmite-like' morphology. Ni-P alloys with low phosphorous content are etched more completely, with large crater formation as large portions of the alloy are dissolved. ${ }^{18}$ As the $\mathrm{P}$ content increases, it is more difficult for large swaths of Ni-P to be etched and hence narrow sharper features are observed. The high absorptance of present coatings is associated with unique surface morphology consisting of a dense array of microscopic, conical pores perpendicular to the surface. The pore diameter, pore depth and pore spacing range from a fraction of micrometer to a 
few micrometers or about a fraction to several wavelengths of light. Consequently, the pores trap any incident light in wide spectral range. ${ }^{19}$

Cross sectional SEM micrograph of coatings were illustrated in Fig. 3. As seen in Fig. 3 (a), as plated Ni-P coating was very uniform and it has $15 \mu \mathrm{m}$ thickness. However, it is not uniform after blackening process. This observation is in agreement with results of roughness test.
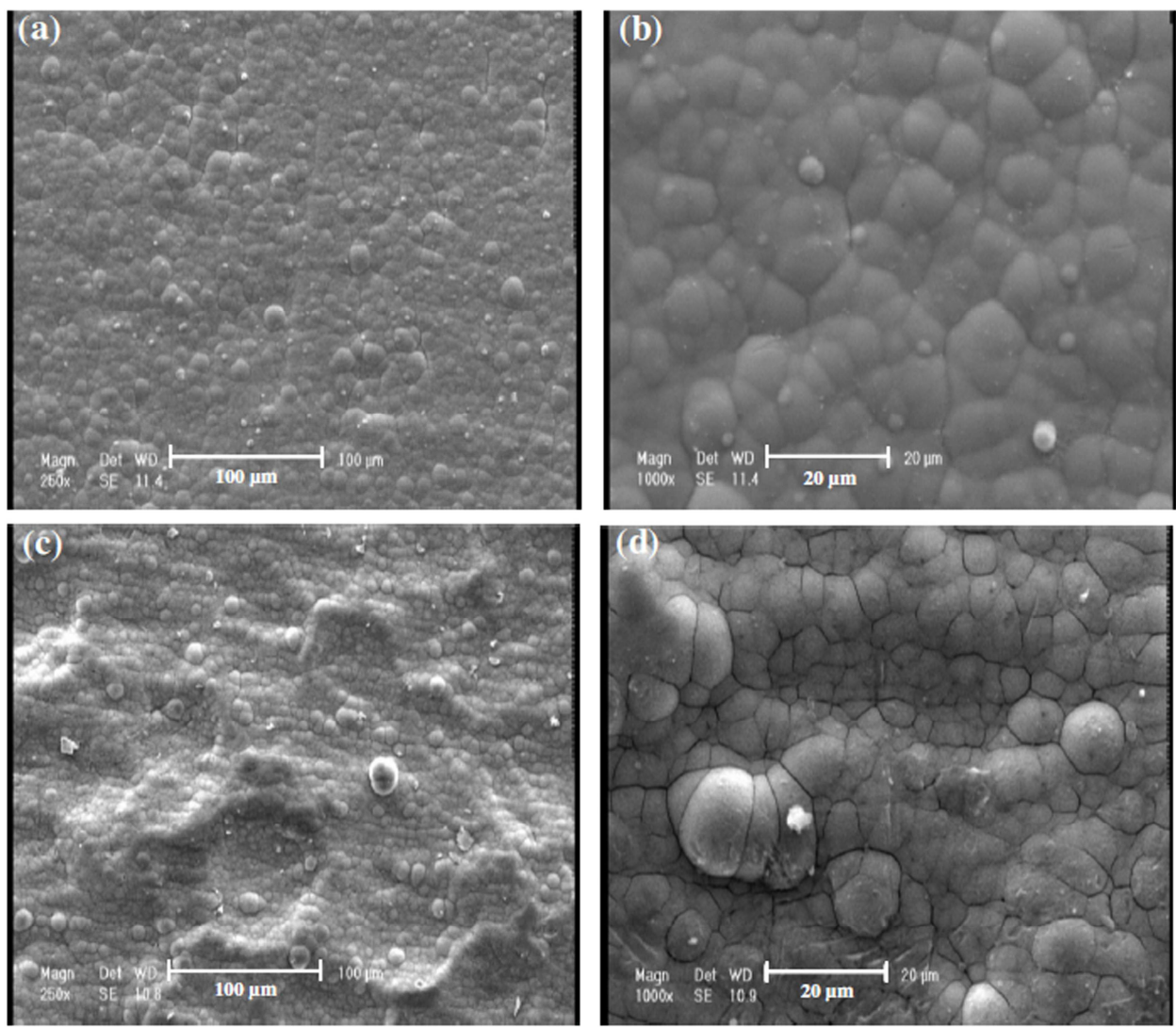

Fig. 2. SEM micrographs of electroless Ni-P coating surface: (a) and (b) as plated, (c) and (d) blackened. 

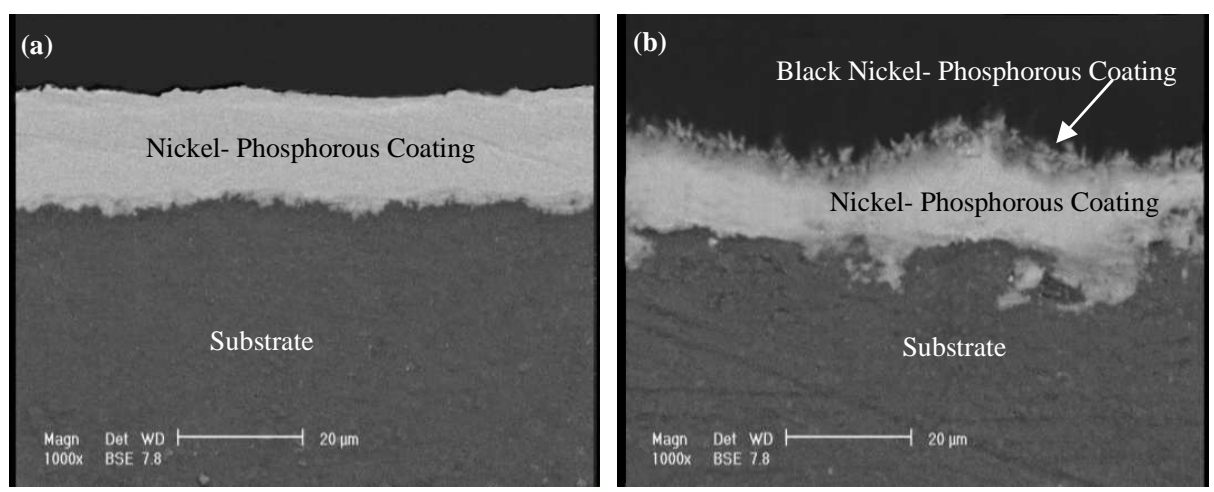

Fig. 3. Cross sectional SEM micrograph of coatings: (a) as plated and (b) blackened.

\subsection{Evaluation of optical properties}

Reflection vs. wavelength diagrams of the coatings are illustrated in Fig. 4. Reflection of the coatings was measured in solar visible wavelength $(300-2000 \mathrm{~nm})$. Normal solar absorptance values were calculated using eq. (2):

$$
\alpha_{S o l}=\frac{\int_{0.3}^{2} I_{S o l}(\lambda)(1-R(\lambda)) d \lambda}{\int_{0.3}^{2} I_{S o l}(\lambda) d \lambda}
$$

Where $\alpha_{\text {sol }}$ is normal solar absorption, $I_{\text {sol }}$ is direct normal solar irradiance and $\mathrm{R}$ is reflectance.

The solar absorption, $\alpha_{\mathrm{sol}}$; is theoretically defined as a weighted fraction between absorbed radiation and incoming solar radiation. The direct normal solar irradiance, $\mathrm{I}_{\mathrm{sol}}$; is defined according to the ISO standard 9845-1 (1992) where an air mass of 1.5 is used.

Solar absorption of the coatings was calculated from reflection vs. wavelength diagram (Fig. 4) and eq. (2) and these values are given in table 3. It is obvious that, absorption values of black electroless coatings are higher than PVD commercial coating and black electroless coating with heat treatment has highest absorption in these samples. Blackening rate of this sample was highest than other one due to crystallization and decrease corrosion resistance of the coating after heat treatment. High absorption of black electroless Ni-P coatings are due to special morphology after blackened companied with high roughness of this coatings. The black color of $\mathrm{Ni}-\mathrm{P}$ coating is due to this unique surface morphology as well to the formation of nickel oxides (NiO, Ni2O3) and some nickel phosphate. ${ }^{11}$ 


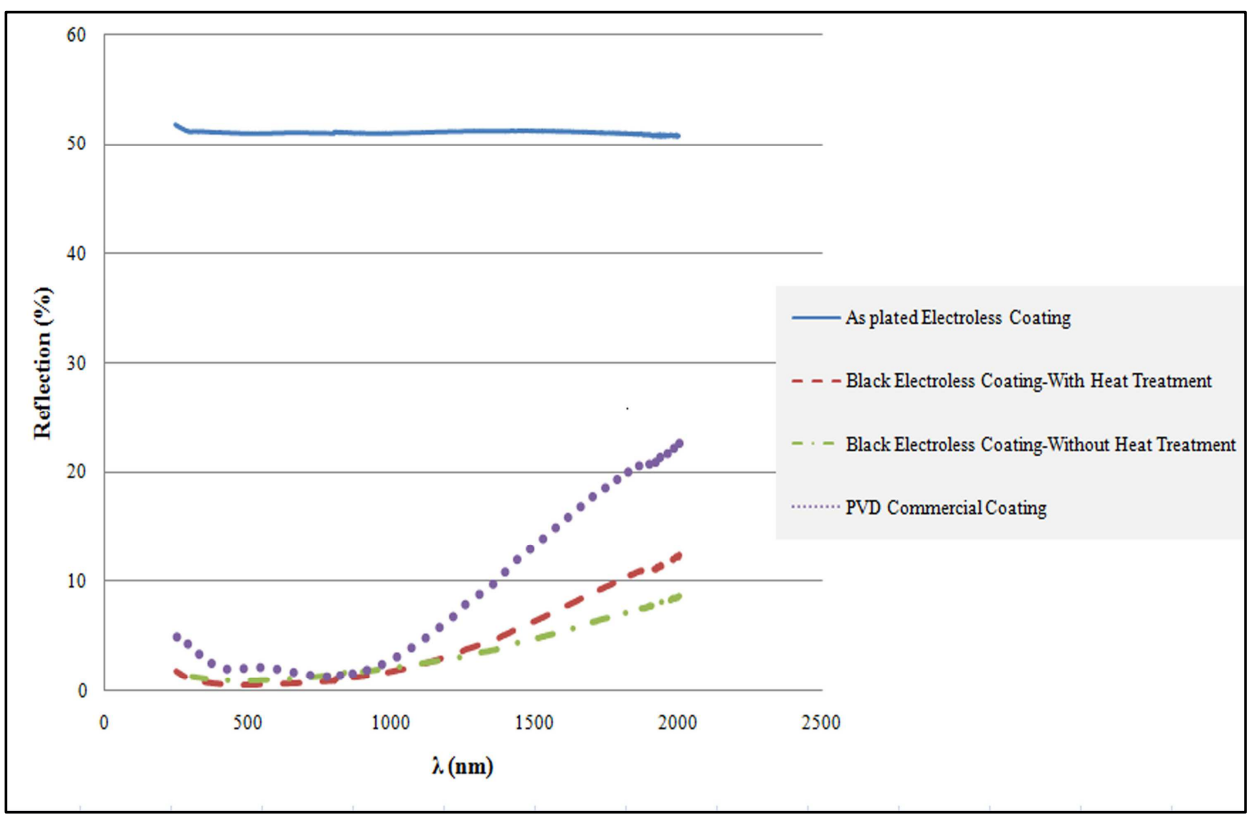

Fig. 4. Reflection of coatings vs. wavelength.

Table 3. Solar absorption of coatings.

Sample

As-plated electroless coating

PVD commercial coating

Black electroless coating, without heat treatment

Black electroless coating, with heat treatment
Solar absorption $\left(\alpha_{\mathrm{Sol}}\right)$

0.49

0.95

0.98

0.99

\section{Conclusions}

1. Heat treatment of electroless Ni-P coating on $\mathrm{Al}$ substrate at $300^{\circ} \mathrm{C}$ for $3 \mathrm{~h}$ lead to deposition of nickel phosphide and it increased hardness of coatings from 580 $\mathrm{VHN}_{0.1}$ to $1050 \mathrm{VHN}_{0.1}$.

2. After blackening process, roughness of surface increased.

3. Absorption values of black electroless coatings were higher than PVD commercial coating.

4. Heat treatment could increase blackening rate of samples due to formation a crystallized structure.

5. Black electroless Ni-P coating with heat treatment had highest absorption than other coatings. 


\section{References}

1. A.R. Shashikala, A.K. Sharma, D.R. Bhandari, Solar Energy Mater. \& Solar Cells, 91, 629_ 635, (2007).

2. G. Katumba, L. Olumekor, A. Forbes, G. Makiwa, B. Mwakikunga, J. Luf, E. Wackelgard, Solar Energy Mater. \& Solar Cells, 92, 1285- 1292, (2008).

3. E. Valova, J. Dille, S. Armyanov, J. Georgieva, M. Marinov, J.L. Delplancke, O. Steenhaut, A. Hubin, Surf. Coat. Technol. 190, 336- 344, (2005).

4. C.K. Lin, H.T. Hsu, C.T. Chen, T.J. Yang, Thin Solid Films, 516, 355-359, (2007).

5. G. Jiaqiang, W. Yating, L. Lei, S. Bin, H. Wenbin, Mater. Letters, 59, 1665-1669, (2005).

6. H. Ma, F. Tian, D. Li, Q. Guo, J. Alloys Compd. 532, 1-4, (2008).

7. W. Riedel, Electroless nickel plating (ASM International, Ohio, 1991).

8. E.S. Cabrera, C. Villalobos-Gutierrez, I. Irausquin, J. La Barbera-Sosa, G. Mesmacque, International J. Fatigue, 28, 1854-1866, (2006).

9. J.T.W. Jappes, B. Ramamoorthy, P. Kesavan Nair, J. Mater. Sci. Technol. 169, 308-313, (2005).

10. H.A. Sorkhabi, S.H. Rafizadeh, Surf. Coat. Technol. 176, 318-326, (2004).

11. D. Takacs, L. Sziraki, T.I. Torok, J. Solyom, Z. Gacsi, K. Gal-Solymos, Surf. Coat. Technol. 201, 4526-4535, (2007).

12. M. Crobu, A. Scorciapino, B. Elsener, A. Rossi, Electrochimica Acta, 53, 3364-3370, (2008).

13. J. N. Balaraju, V. E. Selvi, V. K. William Grips, K. S. Rajam, Electrochim. Acta, 52, 10641074, (2006).

14. P. Peeters, G. Hoorn, T. Daenen, A. Kurowski, G. Staikov, Electrochimica Acta, 47, 161-169, (2001).

15. G. Cui, N. Li, D. Li, J. Zheng, Q. Wu, Surf. Coat. Technol. 200, 6808-6814, (2006).

16. W.L. Liu, S.H. Hsieh, T.K. Tsai, W.J. Chen, S. Wu, Thin Solid Films, 510, 102-106, (2006).

17. M.L. Cantu, A.M. Sabio, A. Brustenga, P.G. Romero, Solar Energy Mater. \& Solar Cells, 87, 685-694, (2005).

18. B. Szczygiel, A. Turkiewicz, J. Serafinczuk, Surf. Coat. Technol. 202, 1904-1910, (2008).

19. V. Saxena, R. Uma Rani, A.K. Sharma, Surf. Coat. Technol. 201, 855-862, (2006). 